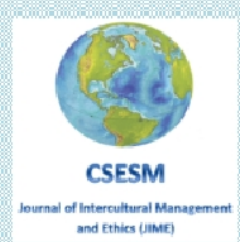

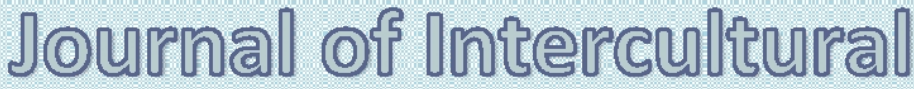

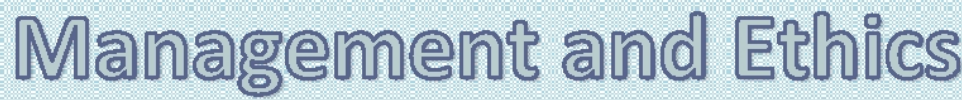

\author{
I0ME
}

ISSN 2601 - 5749, ISSN-L 2601 - 5749

Center for Socio-Economic Studies and Multiculturalism

lasi, Romania

WWW csesmioirg 


\section{TABLE OF CONTENT}

Editorial

Iulian Warter

Where Did Culture Come From? Evolutionary Foundations of Cultural Diversity

Paulo Finuras

Crash: Boeing and the Power of Culture

Thomas D. Zweifel, Vip Vyas

Political Culture, Social Polarization and Electoral Behavior. The Last Decade in Romanian

Political System

Silviu-Petru Grecu

The Principles of Transparency and Judging Others Favorably: The Talmudic View

Hershey H. Friedman, Robert B. Fireworker

Some Issues Regarding the Ethics of the Management at Romanian State-Owned

Companies .55

Baluta Aurelian Virgil, Rada Alexandru Cristian

How Does Logistics Command of the Military Navy Support Local Development and

Cultural Integration?

Rosa Caiazza

Illusion and Disillusion. Case Studies about the Constitution of a New Political Party in

Romania

Alexandru Muraru

How Could We Overcome the Feeling Of Insecurity? Explorations in the Spectrum of Polyscopic Consciousness

Anton Carpinschi

The Employees' Perceptions, Practices and Experiences Regarding the Strategic Process

Carried Out In the Public Hospitals

Ana Niculita 


\title{
CRASH: BOEING AND THE POWER OF CULTURE
}

\author{
Thomas D. Zweifel, PhD \\ University of St. Gallen (HSG) \& ThomasZweifel.com, Switzerland \\ E-mail: thomas@thomaszweifel.com \\ Vip Vyas \\ INSEAD Knowledge, Hong Kong \\ E-mail: vip.vyas@distinctive-performance.com
}

We cannot fix our problems

at the same level

at which we created them.

-Albert Einstein

\begin{abstract}
Two Boeing 737 MAX aircraft crashed twice within six months, killing 167 and 189 passengers respectively. What was the root cause the two crashes had in common? This article finds that at its source, the problem was neither technical nor financial, but human. More precisely, the article makes the case that the failure of the Boeing 737MAX was a result of a corporate culture and mindset. As the management theorist Peter Drucker used to put it, culture eats strategy for breakfast: The most brilliant plans come to naught if the cultural force-field is aligned against them. Ultimately, Boeing is not alone. Building on an earlier finding that any organization is essentially a network of conversations (Zweifel, 2019), we argue that many, if not most, megaprojects (defined as major capital development projects with a budget of at least US\$ 1 billion) suffer from a cultural context, consisting of conversations that run invisibly - and hence even more powerfully - in the background, in what we call the project's "Black Box." If megaproject stakeholders and managers are to steer megaprojects to success, they need an expanded "Dashboard" to monitor and manage these hidden factors along the entire megaproject process.
\end{abstract}

Keywords: Boeing, megaprojects, culture, ethics, leadership

\section{Introduction}

On 10 March 2019, at 8:38am local time, Flight ET302 an Ethiopian Airlines plane took off from Addis Abeba for a two-hour flight to Nairobi.

What happened next is painful to read. It is an inescapable spiral toward death, like watching an accident happening in slow motion. The pilots struggled for five minutes with the plane's automated control system.

That same minute, at 08:38, a sensor on the pilot's side indicates - falsely - that the plane is close to stalling, triggering MCAS and pushing down the nose of the plane.

At 08:39-40, the pilots try to counter this by adjusting the angle of stabilizers on the tail of the plane using electrical switches on their control wheels to bring the nose back up. nose down.

At 08:40, they disable the electrical system powering the software that pushed the

At 08:41 The crew attempt to control the stabilizers manually with wheels - difficult to do while travelling at high speed.

At 08:43, when this doesn't work, the pilots turn the electricity back on and try to move the stabilizers again. However, the automated system engages yet again and the plane 
goes into a dive from which it never recovers (Ministry of Transport Etiopia, 2020). All 167 people on board are killed.

Among the victims were 32 Kenyans, 18 Canadians, nine Ethiopians and eight Americans, plus people from Austria, Belgium, China, Egypt, France, Germany, India, Ireland, Israel, Italy, Morocco, Norway, Poland, Russia, Slovakia, Spain, Sweden, Togo, and the United Kingdom. UN Secretary-General António Guterres described the crash as a "global tragedy". A large number of passengers were affiliated with the UN and/or had been on their way to an environment conference in Nairobi.

Investigators ruled out wrongdoing by the pilots, who had acted flawlessly, and by Ethiopian Airlines, which is seen as Africa's preeminent airline and enjoys a strong professional reputation.

Sadly, the crash in Addis was the second crash in less than half a year. Just in October 2018, a Lion Air flight had crashed in Indonesia, leaving 189 dead.

The U.S. Federal Aviation Administration (FAA), investigating the Ethiopian Airlines crash together with the Ethiopian National Transportation Safety Board, found that evidence collected and satellite data showed both flights behaved "very similarly." "The evidence we found on the ground made it even more likely the flight path was very close to Lion Air's," said Dan Elwell, acting FAA administrator (BBC News, 2019).

Another chilling similarity: Both planes that crashed were Boeing 737 MAX.

What was the source of the crash? What went wrong?

\section{"Software Issue"?}

Boeing claimed the crash cause was a software issue and announced it would upgrade the flight simulator program. But the company's assertion is disputed. Trevor Sumner, CEO of Perch Experience, whose brother-in-law Dave Kammeyer is both a pilot and software engineer, took to Twitter to argue that Boeing's "software upgrade" was a farce.

"Some people are calling the 737MAX tragedies a \#software failure. Here's my response: It's not a software problem.

- It was an economic problem that the 737 engines used too much fuel, so they decided to install more efficient engines with bigger fans and make the 737MAX.

- This led to an airframe problem. They wanted to use the 737 airframe for economic reasons, but needed more ground clearance with bigger engines. The 737 design can't be practically modified to have taller main landing gear. The solution was to mount them higher \& more forward.

- This led to an aerodynamic problem. The airframe with the engines mounted differently did not have adequately stable handling at high AoA to be certifiable. Boeing decided to create the MCAS system to electronically correct for the aircraft's handling deficiencies.

- During the course of developing the MCAS, there was a systems engineering problem. Boeing wanted the simplest possible fix that fit their existing systems architecture, so that it required minimal engineering rework, and minimal new training for pilots and maintenance crews. (...)

- On both ill-fated flights, there was a sensor problem. The AoA vane on the 737MAX appears to not be very reliable and gave wildly wrong readings. 
- On \#LionAir, this was compounded by a maintenance practices problem. The previous crew had experienced the same problem and didn't record the problem in the maintenance logbook.

- This was compounded by a pilot training problem. On LionAir, pilots were never even told about the MCAS, and by the time of the Ethiopian flight, there was an emergency AD issued, but no one had done sim training on this failure.

- This was compounded by an economic problem. Boeing sells an option package that includes an extra AoA vane, and an AoA disagree light, which lets pilots know that this problem was happening. Both 737MAXes that crashed were delivered without this option. No 737MAX with this option has ever crashed.

- All of this was compounded by a pilot expertise problem. If the pilots had correctly and quickly identified the problem and run the stab trim runaway checklist, they would not have crashed.

- Nowhere in here is there a software problem. The computers \& software performed their jobs according to spec without error. The specification was just shitty. Now the quickest way for Boeing to solve this mess is to call up the software guys to come up with another bandaid. (...)

- When the software band-aid comes off in a 500mph wind, it's tempting to just blame the band-aid." (Mish Talk, 2019)

Until the second accident, the 737 MAX had been Boeing's fastest-selling plane in the company's history. More than 4,500 planes had been ordered by 100 different operators worldwide.

Now, scores of airlines canceled their orders. Boeing's stock value plummeted . One year later, Boeing asked a representative for the families of crash victims if it would be appropriate for Boeing's CEO Dennis A. Muilenburg to attend the memorial.

The response was swift. "He is not welcome here," said Zipporah Kuria, whose father, Joseph Waithaka, was killed in the Ethiopian Airlines crash. "Whenever his name is said, people's eyes are flooded with tears." (Kitroeff \& Gelles, 2019)

\section{No End in Sight}

$$
\begin{array}{r}
\text { If you want to be a millionaire, } \\
\text { start with a billion dollars } \\
\text { and launch a new airline. } \\
\text { - Richard Branson }
\end{array}
$$

Alas, that was not to be the end of the Boeing drama. A string of failures hampered Boeing 777 aircraft too. In December 2020, an engine failed during a Japan Airlines flight bound for Tokyo. Japan's Transport Safety Board said a fan blade that had broken off from the engine showed signs of metal fatigue. Another blade was broken roughly in half.

On a weekend in February 2021, the engine powering a United Airlines flight broke apart over a town near Denver. And in another incident on the very same day, a Boeing plane dropped engine parts after a midair explosion over the Netherlands. Longtail Aviation Flight 5504, a cargo plane, scattered small metal parts over Meerssen, causing damage and injuring a woman shortly after takeoff.

There were similarities between the incident in Japan and the one in Colorado. All three involved Pratt \& Whitney engines. These incidents prompted fresh scrutiny by US, Japanese and Dutch regulators that is still ongoing as of this writing. 


\section{Speed and Profits Over People and Safety}

Boeing fired Muilenburg after the 737 MAX calamity. But that action did little to address the source of the crashes. The writing had been on the wall for a long time. Internal documents on the 737 MAX Boeing released in January 2020 feature late-night trash talk between two Boeing pilots who mocked federal regulators, airline officials, suppliers and their own colleagues as "idiots," "clowns," or "monkeys."

Many of the messages are from then-737 chief technical pilot Mark Forkner, including some late-night instant message exchanges with his deputy, Patrik Gustavsson.

In one exchange, with Forkner sometimes drinking Grey Goose vodka - "I just like airplanes, football, chicks and vodka, not in that order," he wrote - and Gustavsson preferring Bowmore Scotch, both talk loosely about their bosses and everyone else they have to deal with in varying derogatory ways that are not fit to print in an academic journal.

One pilot who gave a presentation to FAA staff mocks their lack of technical knowledge: "It was like dogs watching TV." In another message, the 737 MAX is described as "designed by clowns, who are in turn supervised by monkeys."

"Would you put your family on a MAX-simulator trained aircraft?" one pilot asks, then answers himself: "I wouldn't." His colleague agreed.

India's air safety authority, the Directorate General of Civil Aviation (DGCA), is "apparently even stupider" than another unnamed foreign regulator. And one pilot notes, in reference to dealings with the FAA, that "I still haven't been forgiven by God for the covering up I did last year."

"These revelations sicken me," said Michael Stumo, father of 24-year-old Samya Stumo of Massachusetts, United States, who died in the Ethiopian Airlines flight. "The culture at Boeing has eroded horribly," he added. "My daughter is dead as a result."

Of course the lead pilot's lawyer dismissed the more memorable quotes as bravado, nothing more than some hard-charging guys blowing off steam after work. And Boeing disowned the communications, blaming them on a few rogue employees.

But other, more sober and more damning, internal emails reveal that the pilots were under intense pressure from the MAX program leadership. They suggest a troubling culture that put speed above safety. And they point to serious problems with how the MAX was developed and certified.

Robert Clifford, lead lawyer for the Ethiopian Airlines victims, said the documents will "be used by the families of the victims to show a jury that Boeing was reckless and put profits before safety."

Members of the U.S. House of Representatives were particularly incensed by one document showing that, in order to avoid any need for additional pilot training, Boeing downplayed to the FAA the significance of the new flight control software on the MAX known as the Maneuvering Characteristics Augmentation System (MCAS) - that was implicated in both crash flights.

House Transportation and Infrastructure Committee vice-chair and chairman of its Subcommittee on Aviation, Rep. Rick Larsen (D-Washington), said these "efforts to characterize the MCAS software as seemingly inconsequential were a serious mistake."

And that was not the end of it. When Indonesian carrier Lion Air in 2017 asked for simulator training for its pilots, apparently at the suggestion of that country's regulator, chief technical pilot Forkner scrambled to convince the airline that it shouldn't do so. $\mathrm{He}$ approached DGCA and argued that other regulators didn't require sim training, so why should Indonesia.

This manipulation by Boeing of both its airline customer and a foreign regulator looks damning in hindsight, especially when the first crash was a Lion Air jet. Simulator training might well have gone some way to compensating for the over-reliance on cockpit automation 
and a lack of manual flying experience by pilots at some low-cost carriers overseas, which has emerged as an issue after the two crashes.

Boeing conceded as much in January 2020 when it reversed course and recommended simulator training for all pilots before the MAX returns to service.

\section{The Cover Up Exposed}

"Boeing was the place. I mean, they were the place to work, you know?" whistle-blower John Barnett, known as "Swampy," told The New York Times.

And oh my God, it was amazing - when I put that Boeing shirt on, how my chest puffed out. I'd walk into a store around here, and they're like, oh, you work for Boeing? That is awesome. And thank you all so much. And you just mean so much to this area. And it was just awesome. And it's just — [SIGHS] we don't have that anymore here. Nobody does. I mean, everybody I talk to in Boeing, they're embarrassed to work there, most times. It's just — it's gone. (Barbaro, 2019)

There was pressure on the factory floor that created a litany of other problems, for example debris from construction on Boeing's Dreamliner planes at the Charleston, South Carolina factory. Swampy's job was to inspect airplanes to make sure nothing was left behind inside the aircraft. "So I was called out to an airplane to look at an issue," Swampy said. "And that's when we discovered all this debris, these 3-inch long titanium slivers laying around. It's just debris everywhere." During his inspection, he discovered that these metal slivers were hanging over the wires that control the plane. "The risk here is that these metal slivers will migrate into power panels, any kind of power, or any kind of electronic equipment, and short it out and cause a fire. And if it's at 40,000 feet, that's a problem." (Barbaro, 2019)

Swampy took photos and brought the issue to his manager. In response, "I was removed from it." The manager took him off that plane and gave it to someone else to inspect. Did that plane ever get cleaned? No. "It was delivered without being cleaned." And it was not just metal shavings. Multiple whistle-blowers talked about nuts, bolts, fasteners, rags, bubblewrap, trash, tools, even a chewing gum or a ladder: A ton of stuff was left in the bowels of these aircrafts.

"There's a lot of pressure to meet schedule," Swampy said. Managers get judged by their superiors based on the number of jobs they complete on an hourly basis. "And it's held against them if they create defects. So, you know, there's an incentive not to report your defect that you created because it's gonna be held against you." (Barbaro, 2019)

Boeing denied vehemently that they put speed above safety. And to be fair, no Dreamliner has ever crashed. But the question remains, Has the company put profits above safety? Has it put its customers, and ultimately all passengers in its aircraft, in harm's way?

\section{A Dashboard for Complex Systems}

The Boeing tragedy above is a tiny sliver of the available information, distilled from reams of in-depth crash investigation paperwork - millions of pages - produced after the crashes. When mega-projects go wrong, the underlying hidden structure of the failure can be distributed across so much data that it obscures the understanding of the fiasco and its root causes.

What if we could see the entire story unfolding on a single page, distill information into insight, and shift from laundry lists to actionable intelligence? All too often, the pilots in the cockpits of megaprojects (to stay with the Flight-Path metaphor) do not have the right 
dashboard to steer the plane to its destination. Sure, the consequences are not always death and destruction as in the case of the $37 \mathrm{MAX}$ (although at times they are, as other megaprojects in power plants and infrastructure, healthcare and the life sciences demonstrate). But when project pilots don't have their hands on the proper levers and dials, the real-world consequences are always dire. The crash is a metaphor for what happens in many, even most, large-scale projects. Instead of getting to their destination, they veer off the flight path and get into trouble: going over budget, going over time or else not delivering the desired results.

\section{5\% Failure Rate}

The megaproject expert Bent Flyvbjerg has developed a comprehensive database of megaprojects (Flyvbjerg, 2014). Focusing on cost overruns, his statistics amount to an indictment of our inability to deliver on complex endeavors. The numbers are sobering: 65 percent of all megaprojects fail (Merrow, 2011). Table 1 shows a pattern of failures across a wide range of sectors.

\begin{tabular}{|c|c|}
\hline Project & Cost Overrun (\% over budget) \\
\hline Suez Canal, Egypt & 1,900 \\
\hline Scottish Parliament Building, Scotland & 1,600 \\
\hline Sydney Opera House, Australia & 1,400 \\
\hline Montreal Summer Olympics, Canada & 1,300 \\
\hline Concorde supersonic aeroplane, UK, France & 1,100 \\
\hline Troy and Greenfield railroad, USA & 900 \\
\hline Excalibur Smart Projectile, USA, Sweden & 650 \\
\hline Canadian Firearms Registry, Canada & 590 \\
\hline Lake Placid Winter Olympics, USA & 560 \\
\hline Medicare transaction system, USA & 560 \\
\hline National Health Service IT system, UK & 550 \\
\hline Bank of Norway headquarters, Norway & 440 \\
\hline Furka base tunnel, Switzerland & 300 \\
\hline Verrazano Narrow bridge, USA & 280 \\
\hline Boston's Big Dig artery/tunnel project, USA & 220 \\
\hline Denver international airport, USA & 200 \\
\hline Panama canal, Panama & 200 \\
\hline Minneapolis Hiawatha light rail line, USA & 190 \\
\hline Humber bridge, UK & 180 \\
\hline Dublin Port tunnel, Ireland & 160 \\
\hline Montreal metro Laval extension, Canada & 160 \\
\hline Copenhagen metro, Denmark & 150 \\
\hline Boston-New York-Washington railway, USA & 130 \\
\hline Great Belt rail tunnel, Denmark & 120 \\
\hline London Limehouse road tunnel, UK & 110 \\
\hline Brooklyn bridge, USA & 100 \\
\hline Shinkansen Joetsu high-speed rail line, Japan & 100 \\
\hline Channel tunnel, UK, France & 80 \\
\hline Karlsruhe-Bretten light rail, Germany & 80 \\
\hline London Jubilee Line extension, UK & 80 \\
\hline Bangkok metro, Thailand & 70 \\
\hline Mexico City metroline, Mexico & 60 \\
\hline High-speed Rail Line South, The Netherlands & 60 \\
\hline Great Belt east bridge, Denmark & 50 \\
\hline
\end{tabular}

Table 1: Large-scale projects and their cost overrun (Flyvbjerg 2014)

Take the Olympic Games, for example. Held every four years (at least before the Covid-19 pandemic), the Olympics is considered the world's premier international sports event, attracting athletes from over 200 nations to participate. Almost all Olympics hosts 
have a long history of massive commercial losses. The notable exception was Los Angeles, which turned a $\$ 200$ million profit in 1984, the only location to have produced a return on investment since 1932 - when the host had also been Los Angeles. In comparison, Beijing in 2008 produced $\$ 3.6$ billion revenues, but $\$ 40$ billion in costs. London in 2012 performed not much better, $\$ 5.2$ billion in revenue and $\$ 18$ billion in expenses. Despite this dismal track record, nations fight each other tooth and nail for the prestige to host the next Games. It is a fascinating example of distorted thinking and optimism bias.

Flyvbjerg, Alexander Budzier and their colleagues (Flyvbjerg et al., 2004) have compared the spiraling cost overruns of hosting the Olympics, and the limited long-term returns, to the catastrophic impact of wars, pandemics and other natural disasters such as earthquakes, on national economies.

Table 1 above shows that the pattern of failures reaches far beyond the Olympics. Less prominent projects suffer in similar ways; in fact they can fare even worse, since they do not happen, or fail, in the fish tank of public scrutiny.

Not all projects veer off the flight path, by the way. To fight the coronavirus, China built a 1,000-bed hospital in ten days. It looks like a miracle, but it's not mysterious. But we have been looking in the wrong place. Why are so many projects going so wrong? What's missing in megaprojects?

\section{What's Missing? The Streetlight Effect}

You may have heard the story: A police officer sees a drunken man searching for something under a streetlight and asks what the drunk has lost. He says he lost his keys. The policeman wants to be helpful, so they both look under the streetlight together. After a few minutes the policeman asks the drunk if he is sure he lost his keys here, and the drunk replies, "No, actually I lost them in the park." The policeman asks, "So why are you searching here?" The drunk shoots back, "Well, it's way too dark in the park. This is where the light is!"

In the world of projects, have we been looking in the wrong place to discover the keys needed for success? Have we focused on the symptoms, but been blind to the root causes? Our answer is yes, absolutely. For decades, and probably since the early days of Taylorism and "Scientific Management," we have looked in the light only. Now, after untold numbers of failed projects, the time has come to go look in the dark.

"Everyone assumes it's the technical skills," said Mark Utting, country manager of Turner \& Townsend Switzerland that has helped manage many megaprojects. "It's not. Megaprojects have super capable people technically. What's missing is an appreciation of softer skills you need to make a team function."

Utting distinguishes between personality types that all have to collaborate on a megaproject, like it or not: "You have architects that are usually inventive, creative, inspiration types. You have contractors who often just want to get stuff done, who say, 'Don't bore me with details.' You have technical engineers who tend to want to solve problems and are intensely detail-focused. And of course you have the client who might be authoritarian, who has the power, who has the money." (Zweifel, personal communication, November 19, 2019). The tension and friction are built right into the structure.

The key success factor is the human side of megaprojects. Projects don't succeed (or fail); people do. In our experience, the link between people and projects is robust (Vyas \& Nannicini, 2017). Simply put:

- When the project leadership is not aligned, the project becomes fragmented.

- When the project proponents lack trust, the project becomes contractual —if not adversarial.

- When people are afraid to speak up, the project becomes risky.

- When the planning lacks clarity, the delivery becomes chaotic. 
- When the delivery team lacks a bold ambition, the performance becomes lackluster.

Only humans can bring urgency and commit themselves to an ambition. If you master the human element, you can go way beyond traditional project implementation and produce performance breakthroughs. But, to use another familiar metaphor: If the only tool you have is a hammer, then every problem you face looks like a nail.

\section{The White Box}

We have seen that the crash of flight ET302, with the ensuing chain of fiascos at Boeing, was far from an outlier. In fact, the story of the flight reveals a systematic and powerful pattern that runs in all projects. To illustrate, imagine a project meeting with the team leader or a townhall with the CEO. The leader comes in and shows a PowerPoint deck with a mission statement, or a senior manager announces the new corporate strategy and objectives that has been decided in the boardroom (Zweifel \& Borey, 2014).

In keeping with our Flight-Path model, we call this the "White Box." In the case of projects, the White Box consists of all the tangible, objective, and visible aspects of a project such as:

- The performance dashboards

- The business case

- The minutes of project board meetings

- The risk matrices

- The project schedule (GANTT chart)

- The Work Breakdown Structures (WBS)

- The engineering documents

- The tendering documents

- The construction drawings

- The safety processes

- The work method statements

- The user testing

- The quality checking and testing

- The defect reports

- The commissioning packs

- The ownership transfer documentation; and

- The reams of other paperwork

The list could go on, but you get the picture. Now, what do you think: Do these items determine people's actions and ultimately results? Do they shape whether the project outcome is a success or a disaster? This is not a rhetorical question.

\section{It's the Black Box, Stupid}

Then there is the background. Consistent with our Fight-Path model, we call it the "Black Box." It is what the people in the meeting think, but are not saying, "Oh boy, here we go again." "These guys in the suits never get their hands dirty, they have no idea of the conditions on the ground." "How do I get out of this one? How can I pass the buck?" "It's the fault of those other guys" (fill in X other department).

The Black Box is what people tell each other at the water cooler, at the coffee machine or copier, after the meeting or after the boss has left: "They never consulted with us, we would have warned them this whole thing is gonna fall flat on its nose. Now they can deal with the consequences." Often this is what people say after work, in the bar when they had 
one beer too many — or, depending on the culture, vodkas or martinis—so they might say things not fit to print in an academic journal.

It is what happened in the past that still lingers in people's minds. "We tried the exact same thing last year and it failed miserably. This will never work."

Ultimately, it is what the German philosopher Martin Heidegger called "what is unthought in the thinker's thought": What are people not even aware of? What thoughts are so far back in the recesses of their brains that they barely notice they are thinking those thoughts? Instead of saying "People think those thoughts," we could almost say, "Those thoughts are thinking them." For example, at an aerospace company we consulted with (not Boeing), we found in an early workshop, after interviewing some 150 managers at all levels, that the Black Box was a conversation that went something like: "Our best days are behind us."

Now that phrase sounds fairly innocuous at first. But come to think of it, it is pernicious. Imagine coming to the office or project site every day, and the background hanging over you is, "Our best days are behind us." How is your work? What new frontiers do you envision? How do you respond to opportunities that emerge? Are you proactive or reactive? Even defensive? You know the answer.

It was not that people thought or said this sentence every day. It ran in the background. And that's precisely why the Black Box had such power over people's thoughts, actions and ultimately results. Now: Are your day-to-day behavior, what you see as possible, and your actions an expression of the mission statement or strategy the leader showed on the PowerPoint slides in the meeting? Or are they rather a reflection of the Black Box? Again, the answer is clear. And the performance and results were directly correlated with that mindset: For example, satellite builds went 100 percent over the time budget, meaning instead of building a satellite in five years as planned, it took the project team a full ten years. The consequences of such performance for client relationships, trust, worker morale, brand and reputation, not to speak of future business, can be easily imagined.

Once the project teams revealed the Black Box and put it on the table, they could invent a new future. They launched a pilot project to turn its performance around. Within 100 days, they cut the time (and cost) overrun from 100 percent to 10 percent - from five years overrun to six months.

\section{Black Box vs. White Box}

The nature of the White Box is very different from that of the Black Box. Whereas the foreground is visible and solid, the background is invisible, yet pervasive. We have long known from Daniel Kahneman and Amos Tversky's work on behavioral economics that the Black Box does not consist of rational choices to maximize expected utility. Rather, it is systematically irrational (Kahneman \& Tversky, 1979). This background is not something you put in place or choose. It's already there. It has always been there, ever since the inception of the project, and perhaps before. It's like the proverbial wallpaper: People don't see it anymore, even though it's right in their faces. And that invisibility in plain sight is precisely why the Black Box has the power to shape the project's culture, people's mindset, what people see as feasible or possible or impossible. It shapes people's attitudes and willingness to take responsibility, make commitments, or keep commitments. It shapes their behaviors, whether they come to meetings on time, whether and how they speak up in meetings. It shapes their actions. And hence it shapes their results.

All organizations and projects have a White Box and a Black Box. And now comes the project killer: Traditional approaches to project management focus almost exclusively on the White Box and ignore the Black Box until it's too late-if ever. 
In the case of the Lion Air crash, it was the dynamics taking place in the background that were at the heart of those fateful events. With ET302, it was the collective condition created in the background that was instrumental in the final, terrible outcome. And here is the rub: Boeing's senior executives did not wake up every morning with the sole intention of creating a toxic work environment. That just wouldn't make sense. After all, they had to rely on others for improvements in performance and demonstrate quarter-on-quarter earnings growth to their shareholders.

The Black Box at Boeing - just like in every other project or organizationdeveloped over time. It is also likely that Boeing executives were at least partially blind to the overall organizational condition they were fostering. It was a condition that overlooked shortcuts, tolerated cover-ups, put pressure on speed above safety, strangled dissent, blinkered individuals into cost-cutting at all costs, promoted deception and deliberate manipulation. It was all of this, coupled with downplaying key risks that led to the loss of 167 lives on that fateful flight.

\section{Upper Panel: The Project White Box ("Process")}

\begin{tabular}{|l|l|}
\hline Elements & Explanation \\
\hline $\begin{array}{l}\text { Project } \\
\text { Governance }\end{array}$ & $\begin{array}{l}\text { The system by which the project is controlled and handed over to operations. Governance } \\
\text { includes the mechanisms by which decisions are made, people are held accountable and the } \\
\text { performance of the project is monitored. }\end{array}$ \\
\hline Business Case & $\begin{array}{l}\text { A business case is typically a well-structured document that presents the rationale for } \\
\text { initiating a project, programme or portfolio. Included in the content is the evaluation of } \\
\text { project benefits, an analysis of costs and risks, alternative options and the preferred solution. }\end{array}$ \\
\hline $\begin{array}{l}\text { Final } \\
\text { Deliverables }\end{array}$ & \begin{tabular}{l} 
These are the outputs that clients expect once the project is complete. \\
\hline Ptrategy
\end{tabular} \\
$\begin{array}{l}\text { The procurement function's methods and procedures to effectively provide the project with } \\
\text { the raw materials, equipment, industrial goods and services needed to effectively complete the } \\
\text { project. } \\
\text { Procurement decisions also cover type of delivery method used, e.g. Turn-Key, Design-Build, } \\
\text { Design-Build-Operate etc. and types of contract payment (fixed price, cost-plus or other } \\
\text { models) to incentivise performance. }\end{array}$ \\
\hline $\begin{array}{l}\text { Execution } \\
\text { Capability }\end{array}$ & $\begin{array}{l}\text { The critical skills and ability to execute the project's scope of work and deliver on the outputs } \\
\text { expected by the client. }\end{array}$ \\
\hline
\end{tabular}

Table 2: The Project White Box

\section{Lower Panel: The Project Black Box}

While the upper panel is mechanistic and linear, the lower panel is organic and complex. In a project's Black Box we search for the subconscious and unconscious drivers of human behaviors and actions, and ultimately of results. This means delving into scientific disciplines such as behavioral economics, cognition, perception, biases, heuristics - factors that determine everyday individual and group behaviors. Unlike the upper panel, the lower panel is intangible and "out of sight." It is this hidden part of the proverbial iceberg that we explore in more detail. Table 3 shows examples of sub-conscious beliefs or conversations that can be found in the Black Box, in the background of any project.

Opening the Black Box: Background Beliefs

\begin{tabular}{|l|l|l|}
\hline $\begin{array}{l}\text { Performance Success } \\
\text { Factor }\end{array}$ & Constrains & Expands \\
\hline
\end{tabular}




\begin{tabular}{|c|c|c|}
\hline & \multicolumn{2}{|c|}{$\leftarrow \leftarrow$ Spectrum of the Black Box $\rightarrow \rightarrow$} \\
\hline Leadership & $\begin{array}{l}\text { "She's the boss..." "My hands are tied..." } \\
\text { "The issue is above my pay-grade..." }\end{array}$ & $\begin{array}{l}\text { "I'll connect with the right people and } \\
\text { make sure the project tackles this." }\end{array}$ \\
\hline Motivation & $\begin{array}{l}\text { "This project is just a job.." "I'm just a cog } \\
\text { in the wheel..." }\end{array}$ & $\begin{array}{l}\text { "We're re-designing the economy and } \\
\text { future of X." }\end{array}$ \\
\hline Trust Barriers & $\begin{array}{l}\text { "The client / contractor / government is out } \\
\text { to shaft us..." }\end{array}$ & $\begin{array}{l}\text { "We're both in a difficult situation. Let's } \\
\text { see what we can work out." }\end{array}$ \\
\hline Fear of Speaking Up & $\begin{array}{l}\text { "We can't possibly say that or raise that } \\
\text { issue..." "Don't rock the boat..." }\end{array}$ & $\begin{array}{l}\text { "Lets create an amnesty to get on the } \\
\text { table what's really going on." }\end{array}$ \\
\hline Accountability & $\begin{array}{l}\text { "It's not my job, someone else will deal } \\
\text { with it..." "Let's hope for the best..." }\end{array}$ & "The buck stops with us." \\
\hline Culture & Dead silence in the room... & $\begin{array}{l}\text { People contributing and generating } \\
\text { practical insights. }\end{array}$ \\
\hline
\end{tabular}

Table 3: The Project Black Box: Sample Background Conversations

We urge researchers and practitioners to systematically assess the impact of such belief-systems on areas of performance such as: quality of the business case, governance, procurement, delivery effectiveness, task ownership, amount of rework, costs, schedule and stakeholder satisfaction. Not to mention shareholder value and the stock price.

\section{Conclusion}

A full 65 percent of megaprojects fail. We argue that the White Box (the project's visible or technical foreground) is not what derails most projects. It is in the Black Box (the project's background) where all the processing, heuristics and hidden talk happen. It is where the beliefs, biases and (sometimes untapped) brilliance of the organization live. It is in the background that we find a whole range of mental dynamics and barriers determining the performance of the White Box in the foreground.

The way the brains and minds of those participating in the change effort or project are configured and oriented makes all the difference to project success (or failure). Steering a project successfully requires effective management of both the White Box and Black Box, the foreground and the background. And project leadership matters for this. Why? Take an organization that refuses to change. Who is usually most threatened by change or innovation? And who has the most incentives from keeping the status quo in place? You guessed it: top and senior management (Zweifel, 2012).

But our experience gives cause for some optimism. Over three decades of working with megaprojects, we have seen again and again that there are interventions project managers and executives can take in addressing their corporate and project Black Box and overcoming organizational blindness (Sathe, 1985; Vyas \& Nannicini, 2017; Zweifel \& Borey, 2014):

- Power of Inquiry: Enhancing individual and organizational awareness by dialogues within organizations to highlight both hidden limitations and untapped opportunities, e.g. "If constraint X were removed, what impact could it have on revenues?"

- Future/Outcome-Based Thinking: Working backward from the desired business outcomes can reveal a multitude of different pathways to deliver on the business intent. 
- Strategic Empathy: Standing in the shoes of existing and new competitors and anticipating their potential moves to undermine a firm's strategic direction can be useful in revealing and highlighting flaws and gaps in current logic and approach.

- Power of Vision: Altering the context of key change initiatives so that the organization sees the possibility being bigger than the threats and risks.

- Self-Leadership: Identifying those "hot buttons" that set you off and developing practices for self-regulation.

We close with one question worth considering: Are project leaders creating the conditions to foster innovation and creativity, communication and collaboration, action and performance? Or is their project wasting its vital resources on worry, fear, blame, selfprotection or CYA (Cover Your A--)?

\section{References}

Barbaro, M. (2019, April 23). The Whistle-Blowers at Boeing. The New York Times. https://www.nytimes.com/2019/04/23/podcasts/the-daily/boeing-dreamlinercharleston.html

BBC News. (2019, 5 April). Boeing 737 Max: What went wrong?. https://www.bbc.com/news/world-africa-47553174

Flyvbjerg, B. (2014). What You Should Know About Megaprojects and Why: An Overview. Project Management Journal, 45(2).

Flyvbjerg, B., Budzier, A., Ansar A., Buhl S., Cantarelli C., Garbuio M., Glentin C., Holm M.S., Lovallo D., Lunn D., Molin E., Rønnest A., Stewart A. \& Wee, B. (2004). Five Things You Should Know About Cost Overrun. Transportation Research Part A: Policy and Practice, 118, 174-190.

Kahneman, D., \& Tversky, A. (1979). Prospect Theory: An Analysis of Decisions Under Risk. Econometrica, 47, 313-327.

Kitroeff, N., \& Gelles, D. (2019, December 22). At Boeing, C.E.O.’s Stumbles Deepen a Crisis. The New York Times. https://www.nytimes.com/2019/12/22/business/boeingdennis-muilenburg-737-max.html

Ministry of Transport Etiopia (2020, 9 March). Aircraft Accident Investigation Preliminary Report, 10 March 2019. https://reports.aviation-safety.net/2019/201903100_B38M_ET-AVJ_Interim.pdf

Mish Talk. (2019, 17 March). Boeing 737 Max Major Design Flaws, Not a Software Failure. https://mishtalk.com/economics/boeing-737-max-major-design-flaws-not-a-softwarefailure.

Merrow, E.W. (2011). Industrial Megaprojects: Concepts, Strategies, and Practices forSuccess. New York: Wiley \& Sons.

Sathe, V. (1985). How to Decipher and Change Organizational Culture. In R. H. Kilman, M. J. Saxton \& R. Serpa (Eds), Gaining Control of the Corporate Culture (pp. 230-261). San Francisco: Jossey-Bass.

Vyas, V., \& Nannicini D. (2017, August 7). Overcoming the Misery of Mega-Project Delivery. https://knowledge.insead.edu/blog/insead-blog/overcoming-the-misery-ofmega-project-delivery-6826

Vyas, V., \& Doughty S. (2017, January 30). Hidden Neural Patterns Could be Limiting Your Performance. https://knowledge.insead.edu/blog/insead-blog/hidden-neural-patternscould-be-limiting-your-performance-5181

Zweifel, T.D. (2012). Culture Clash 2.0: Managing the Global High-Performance Team. New York: SelectBooks.

Zweifel, T.D. (2019). Life's a Box of... Conversations: The Company as a Language Network. Journal of Intercultural Management and Ethics, 2(4), 35-42. 
Zweifel, T.D., \& Borey, E.J. (2014). Strategy-In-Action: Marrying Planning, People and Performance. New York: iHorizon. 